\title{
The Physiology of the March: A Lecture delivered at the Staff College
}

\author{
Lieut.-Colonel C. H. Melville
}

To cite this article: Lieut.-Colonel C. H. Melville (1910) The Physiology of the March: A Lecture delivered at the Staff College, Royal United Services Institution. Journal, 54:394, 1580-1597, DOI: 10.1080/03071841009418147

To link to this article: http://dx.doi.org/10.1080/03071841009418147

\section{册 Published online: 11 Sep 2009.}

Submit your article to this journal $2 \pi$

Џll Article views: 3

Q View related articles $\widetilde{2}$ 


\section{THE PHYSIOLOGY OF THE NARCH.}

A Lecture delivered at the Staff College.

By Lieut.-Colonel C. H. MELVILLE, Royal Army Medical Corps.

Projessor of Hygiene, Royal Army Medical College.

I WILL take as the text of this paper a quotation from the Field Service Regulations of the "German Army, which emphasises somewhat more strongly than do our Regulations the paramount importance of this subject.

Paragraph 303 of the 1900 edition. runs as follows:- "By far the most important factor affecting the efficiency of troops for war is their power of marching. The march is the keystone of all operations, and the success of every undertaking depends very largely on the accuracy of the arrangements made for its performance. In many cases the arrival of a body of troops at the right place, at the right time, and in good fighting trim, may be the decisive factor in the situation."

I may be thought to be stepping somewhat out of my province in quoting the above regulations, which, of course, refer to marching from its purely military aspect; but I do só of set purpose, for important as marching is to the soldier as a soldier, it is just as important to the soldier as a doctor. Of all the causes which tend to lower the resisting power of the soldier, none is more important, none has greater effect; and none is more inevitable than marching. A commander may save his men from hunger, he may save them from thirst, and he may protect them from exposure, but march they must, and his aim must be to nurse their natural resisting powers to the utmost of his ability by sparing them as much as he can. To quote again from the German Regulations, para. 306 , says : - "However well trained troops may be in the art of marching, they cannot be expected to continue efficient in this respect unless they are spared every demand on their powers of endurance not absolutely necessitated by the object for. which the march is made." "To do this, to spare them these unnecessary demands on their powers of endurance, it is necessary to understand the physiology of the march, that is the effect 
that the act of marching has on the bodily economy of the soldier.

If these effects, and the mechanism by which they are produced, are thoroughly understood and constantly remembered, the march may be a cause not of reduced but of increased powers of resistance.

I propose to consider the question of marching under two aspects:-First, the effects of marching pure and simple, under ordinary service conditions: and secondly, the effect of prolonged and continuous forced marching.

First, then, I will begin with marching pure and simple, and will, to clear the ground, give a definition of what $I$ intend by the word marching. Marching, then, means walking; wearing certain clothes; carrying a certain load, disposed on the body in a certain manner; at a fixed pace, regulated, not by the physical necessities of the individual, but by the average physical character of the body of troops of which he forms a part. That seems rather a complicated way of stating a very simple fact, but I think it will be admitted that all the above particulars are essential to the idea of the marching soldier as distinguished from that of the walking civilian, and it is these particulars which so differentiate the two that constitute the problem of marching as apart from mere walking.

I propose to discuss the above definition step by step, and will, therefore, begin with the first word-walking. Walking is the result of muscular effort; that is, it is caused by the contraction of certain muscles. When a muscle contracts, that contraction is accompanied by two phenomena: visible movement and heat. Now, I wish it to be understood that the contraction, the heat, and the visible movement are all absolutely interdependent, and essential to each other. You cannot have any one of the three without having the other two. You cannot have the heat without the contraction, and the movement, nor can you have the movement without the contraction and the heat, and so on. I will give you an exactly parallel instance. Those who have driven, or had any acquaintance with petrol motors, or other internal combustion engines, know that the visible motion of the piston is due to the combustion in the cylinder of a certain amount of petrol vapour, essentially carbon and hydrogen, and the consequent expansion of the gas, with the production of heat. Now, I want you to understand that these two phenomena are absolutely and entirely similar. In the case of the muscle we have, as the result of a nervous impulse, which corresponds to the ignition spark of the petrol engine, the combustion of certain constituents of the muscle, consisting essentially of carbon and hydrogen, the con-

iThere is, of course, the exceptional case where a muscle contracts against an insuperable resistance, and no movement results; but the rule holds generally good. . 
sequent contraction of the muscle with the production of heat, and as a result the visible movement. The point to which I particularly want to direct you'r attention is the absolutely essential character of the heat produced. There can be no muscular action without the production of heat, any more than there can be an explosion of petrol vapour in the cylinder of a motor car without the production of heat. Now, if one group of muscles only contract, as when I bend my arm, the production of heat is so comparatively slight that it is absorbed by the blood stream, and distributed throughout my body without materially raising my temperature; but though the heat produced is insufficient to raise the temperature of my body perceptibly the heat is still there, and it can, with suitable instruments, be measured in the substance of the muscle that produces it. In addition it is proportional to the work clone. The case becomes, however, very different if we consider the movement of a large number of muscles, and repeat this movement several times, as in the case of walking, rowing, or running. The heat produced in these processes is now so great that it raises the temperature of the body as a whole. To give you an actual instance. In a series of observations made in 1906 by Dr. Pembrey, of Guy's Hospital, and Captain Parker, Royal Army Medical Corps, at Aldershot, on soldiers marching under varying conditions of load carried, clothing, and so on, the temperature of the men. was taken on 359 occasions before and after marching. The temperature of these men was found to have risen on an average to $2.3^{\circ}$. Fahr. above normal. This rise in temperature is purely physiological. It is the absolutely essential accompaniment of the exertion necessitated by the march. Now, it is obvious that if the muscles are continually producing heat, one of two things must result: either the temperature of the body must rise to such an extent that further exertion would be impossible, or the heat must be dissipated in some way or another. Ordinarily, the latter is the case.

The heat developed in the muscles is carried by the blood stream to the surface of the body, where it passes off in three ways:-By the evaporation of the moisture of the breath; by direct radiation and convection from the skin; and by evaporation of the moisture of the perspiration. Of all these the last is by far the most important; that is to say, the heat pro. duced by marching is got rid of, or dissipated, more by means of the evaporation of the perspiration caused by the exercise than in any other way. As I say, ordinarily this occurs, but if in any way the evaporation of the perspiration is interfered with, owing to the air being too damp to take up more moisture, or the body too thickly clad to allow of the moisture evaporating rapidly, the temperature of the body will rise to an injurious extent and a state of "fever," tending eventually to heat stroke will be produced. I will return to this later. What I want to 
emphasise at this point is, that the rise of temperature caused by marching is normal and inevitable, and, in addition, beneficial and necessary, and that it is, under ordinary conditions, passed off from the surface of the body by evaporation. I will return to my analogy of the motor car. As all no doubt know, after a car has been running for a short time the cylinder becomes so hot that special arrangements have to be taken to cool it. These arrangements consist of a system of water circulation, which removes the heat from the cylinder, where it is produced, to the radiator at the front of the car, where the heat passes off from the water by convection. Now, all who have driven cars know that this heat is an absolute necessity, and that till a certain degree of heating is attained, the car will not run its best; also that when everything is running smoothly the temperature once attained is kept constant. The two cases are absolutely parallel. In both man and the motor car you have a certain amount of energy produced, and as a necessary concomitant of that energy, heat. In both this heat is removed from the place of its production, in the one case the muscles, in the other the cylinders, by a circulating fluid; in both the heat is conveyed by this circulating fluid to the surface of the engine, and there dissipated to the surrounding air, by evaporation in the case of man, by convection in the case of the motor car. And in one case, as in the other, if you interfere with the dissipation of heat, by the skin or the radiator, as the case may be, you produce an overheated condition of the engine, which in man we call "fever," or heat-stroke, and in both cases you lay the engine open to further serious injury as a direct consequence of this overheated condition.

Now, the great difference between the civilian walking and the soldier marching is, that the former is at liberty by varying his clothing, his pace, and the load he carries, not only to minimise the production of heat, but to facilitate its dissipation, while in the case of the soldier such liberty is necessarily denied.

If you will turn to the definition of marching, which I gave at the commencement of this paper; you will find that everything that comes after the word "walking " refers to conditions which either add to the amount of heat produced in marching, or interfere with the proper dissipation of that heat. Thus, for instance, the load carried increases the amount of work done, and therefore, the amount of heat produced, the fact that certain clothes have to be worn interferes with the proper dissipation of that heat. . Now, I wish to point out that the factors which interfere with the dissipation of heat are more:important than those.which increase its production, and, at the same time, are far more under control. . As long as the heat produced by marching is allowed to escape freely from the surface of the body, no exertion, which the soldier is ordinarily called upon to undertake,

VOL. LIV. 
will cause any material rise of temperature above what is normal and permissible.

The chief : factor which increases the production of heat is the load carried and the way in which it is carried. I have drawn a diagram (Plate I. $[a]$ ), showing the effect of increasing the load on the production of heat. The observations were made on the same man, over the same ground, on two different days, of approximately the same temperature. On the first occasion the man was in drill order, and his temperature rose less than half a degree Fahrenheit; on the second he was in marching order, and his temperature rose almost a degree. This experiment was carried out in the Long Valley at Aldershot over practically level ground, the load, therefore, had merely to be carried, not lifted. Of course, on a hill side this would be very different, as the work done would be increased by the number of pounds the man had to lift through each foot of the ascent. Every superfluous ounce of weight that a man carries has a definite effect in increasing that man's temperature, and though the increase may not, as long as the load is fairly light; or the march fairly casy, be of any great importance, it must be kept in mind that every successive ounce has a greater effect in raising the temperature than the ounce that went before it, and that this progressive increase gets relatively greater as the weight mounts up.

To show the influence of the weight carried, and the manner in which it is carried on the energy output of the soldier, it has been calculated that the work done in carrying $20 \mathrm{lbs}$. in the hand is three times as great as if the weight were carried symmetrically on the shoulders: The accuracy of this calculation has been confirmed by several observers.

If the load be materially increased to, say, $60 \mathrm{lbs}$., and the march increased in length, and especially if the other conditions of weather, etc., be unfavourable, the temperature may rise very considerably. Thus the German physiologist Zuntz records that a load of $68 \mathrm{lbs}$. - on a march of 15 miles sent the temperature of the men under observation up to 102.5, and in one case as high as io4. He states that the men whose temperatures were 103 and over had flushed, purple faces, a vacant, unseeing stare, and were obviously on the verge of breaking down. He also adds the interesting note that a load of $48 \mathrm{lbs}$. on a very hot day, has the same effect in raising the temperature as a load of $68 \mathrm{lbs}$. on a cool day. The way in which the load is carried is, of course, of enormous importance. A badly balanced load means constant muscular effort to maintain the equilibrium of the body; constant muscular effort means constant production of heat, in this case unnecessary heat. For this reason the weights should be as close to the centre of gravity of the body' as possible. The centre of gravity of an unloaded man, is a little below the navel, and vertically below the point of the shoulder. 'Any weight placed on a man's back 
at once displaces his centre of gravity to a greater or less extent, and the greater the distance to which his centre of gravity is displaced, horizontally or vertically, the greater the effort he has to make at every step to accommodate his muscles to the new conditions; the greater the effort the greater the muscular strain, and the greater the muscular strain the greater the unnecessary evolution of heat. The total weight carried by a man, and more especially any additions to that weight must always be considered in relation to the actual body weight of the man himself.

Take the average man as being 10 stone or $140 \mathrm{lbs}$. when unloaded, it is obvious that the whole internal economy of that man is regulated by the fact that his muscles have, as a rule, that weight of flesh to move along the level or up hill. If to this live weight, to which his muscles are accustomed, you add dead weight, you are asking those muscles to do extra work, to which they are unaccustomed, and which at first they will do uneconomically. As long as the load is not too heavy, practice will train the muscles to accommodate themselves to the new conditions; but there is a certain limit, different for each man, but regulated a great deal by his body weight, beyond which no amount of practice will enable him to carry the load, and still keep sufficient store of energy in hand for any other purpose. That is to say, the carrying of the load becomes his main function, and the power of fighting becomes subsidiary to it. What that limit is has not, so far as I know, ever been actually determined by experiment. It is probably, however, about one-third of the body weight, say 5o lbs., which is roughly the weight carried by our infantry. soldiers.

The temperature produced is affected not only. by the load carried but also by the pace at which it is carried, and in two ways. In the first place it is obvious that if you carry a certain load a certain distance in 10 minutes, and again do the same in 5 minutes, you produce an equal amount of heat on both occasions, since you do the same amount of work on both occasions. On the second occasion, however, you have only half the time to dissipate the heat produced, which naturally accumulates in the body to that extent. There is, however, actually a greater amount of heat produced, for the following reason:- The human engine, like all other engines, has a normal speed at which it does its work with the greatest economy. Any variation of that speed, either above or below the normal is uneconomical, - and more heat is produced relatively to useful work done in either case. As an illustration I would remind you of how much more tiring it is to walk at a pace accommodated to that of a child, than it is to walk at your normal pace.

The fact, therefore, that a man has to accommodate his pace to that of his comrades, affects the amount of heat produced, in comparison, with the amount of useful work actually done, because the work is done less economically. Every man 
has his own pace at which he can cover the ground with the least trouble to himself, any variation in this pace, whether in the direction of accelerating or retarding, increases the amount of heat produced for work actually done.

Other conditions also increase the amount of heat produced. Thus a tired man works less economically, burns more fuel that is, than a fresh one, and the heat produced in the body of a footsore man on the march may be as much as io per cent. higher than that produced in a sound man over the same distance.

We now come to the conditions which interfere with the proper dissipation of heat from the body, of which the principal are: first, the clothing; secondly, the fact that this clothing has to be of uniform character, and cannot be varied to suit personal idiosyncrasies, or beyond certain rather narrow limits, to correspond to the variations of the weather; thirdly, the fact that the man has to march in a mass of other men; and lastly, the weather-that is, the temperature and moisture of the air. All of these, with the exception of the weather, are, of course, more or less under control.

To begin with clothing. All clothing, naturally, interferes with the dissipation of heat from the body, which is the obvious reason why men strip to hard work. It interferes with the dissipation of heat because it interferes with the evaporation of the perspiration and with radiation. Even a very slight difference in the amount of clothing carried will make a very great difference in the rise of the temperature of the wearer. For instance, the same five men were marched from the Cambridge Hospital to Pondtail Bridge and back, on two occasions, in drill order, the only difference being that in one case they wore their jackets, and in the other case they did not. In the latter case their temperatures rose one degree Fahrenheit, in the former one degree and a half. This was the same march as that referred to when I was speaking of the effect on the temperature of increasing the load carried, and it will be seen, Plate I. (c). that the additional heat accumulated in the body, as the result of wearing a jacket on a warm day, was about equivalent to carrying a load of $30 \mathrm{lb}$. on a cold day. A rather important fact. I think the obvious corollary is, that since men wear their jackets they should not only be allowed to, but ordered to open them as much as possible. It is astonishing to me how often you see this not done on mancuvres. With our present infantry equipment this is easy, and one of the greatest advantages in that equipment is, to my mind, this ability to throw open the coat and expose the large evaporating surface furnished by the skin of the chest to the air. In any well-considered equipment there should be no band or strap crossing the body above the waist belt. All straps or bands should be vertical. The coat can then be thrown freely open, and I should, in addition, like to see it provided with buttons, so that the opened flaps could be buttoned back. For the same 
reason it would be an advantage if sleeves were capable of being rolled or buttoned up, so as to expose the skin of the forearm. It is all the more important to do this, that is to make all the use possible of what evaporating areas are accessible, because, by the nature of things, a great many which are open to the civilian are closed to the soldier. Even if the latter could take off his coat there is still the fact that he must carry at least a greatcoat, if not a pack, and where these touch the skin, perspiration at once accumulates because evaporation is impeded.

There is on record a concrete historical instance of the effect of difference in clothing on the endurance of troops. It occurred at the attack on Chin-Kiang-Foo in the first Chinese War. The 98th Regiment, healthy and strong, having just newly landed, ascended the heights dressed according to regulation. The heat was intense, and numbers of men fell dead on the way from heat-stroke. The I8th, 49th, and 55th Regiments, equally exposed to the sun, but with their jackets opened and their stocks removed, did not lose a single man from this cause. Of course, the removal of the stocks must have had some effect, but the main difference was undoubtedly that while the men of the 98 th could not get rid of the heat produced by the march, since the perspiration could not evaporate sufficiently rapidly through their tunics, the men of the other regiments having their jackets open, were able to take advantage of this method of reducing their temperature.

As to the effect of marching in a dense formation on the temperature of the men in the centre of the column, there are as far as I know no accurate observations. If you notice a flock: of sheep being driven along the road, you will see at once the dense cloud of steam that arises from them, and, of course, one knows how a horse steams after a gallop on a cold day. This steam is merely the evaporating perspiration condensed and made visible by contact with the cold air. Now, it is easy to understand that towards the rear of a column the air must, especially if it is a still day, become so saturated with the moisture that has evaporated from the men in front that it will be unable to take up any more moisture from the men further back, who will therefore suffer from an accumulation of heat in their bodies. Obviously this is more likely to occur on a day when the air already contains a great deal of moisture, than on a day which, though hotter, is drier. Now, these factors which impede the dissipation of heat of which I have spoken, so far, are all, to a certain extent, controllable by the commanding officer. There is one factor which cannot be controlled, and that is the weather.

The effect produced by the weather conditions on the temperature of the soldier is due not so much to the heat of the air per se as to the amount of moisture it contains at that temperature. How marked the effect of the two combined can be, will 
be seen from the diagram Plate I. (b), showing the effect of weather conditions. The march is the same as that already mentioned, a distance of 7 miles across the Long Valley and back. This was performed by the same man in drill order on the 3oth August, 1906, and on the IIth March, 1907. The temperature by the wet bulb thermometer was $22^{\circ} \mathrm{F}$. higher on the first occasion than on the second, and the air much damper. The man's temperature rose barely half a degree on the second occasion, and over one degree on the first. That is to say, that the difference in the temperature and moisture above stated had an effect on the accumulation of heat in the body more than equivalent to that produced in the act of carrying 30 lbs. the same distance.

There are other physical effects p'oduced by the act of marching, but before I come to them I wish to emphasise the point, that what chiefly makes the difference between the soldier marching, and the civilian walking, is the fact that the latter can please himself in the measures he takes to dissipate the heat produced by walking, while the former cannot. What he cannot do for himself his officer must do for him in every possible way, and not merely for the man's comfort, but because every unnecessary decimal point of temperature, that is allowed to accumulate in the man's body, not only throws an unnecessary strain on his heart and lungs, but brings him by so much the nearer to heat stroke.

The other physical effects of marching are its effect on the heart, the lungs, and the weight of the body. But these effects are not primary effects, they are all secondary to the fact that marching is a muscular exercise, and as a consequence, that it causes an increased production of heat in the body. To begin with the heart. The heart has to supply blood to the muscles in increased quantity, partly to supply increased fuel to the engine, but also, what is far more important at the moment, to supply increased oxygen to support the combustion that is the concomitant of the muscular action. This increased quantity of blood demands an increased activity of the heart, and, consequently, we find as one of the early results of marching a quickened heart beat. This increases in rapidity fairly. regularly with the rise of temperature, and remains fairly constant once it has attained the rapidity demanded by the call of the muscles for oxygen. There are other factors probably that affect the rate of the heart, but for our present purpose we can consider the above as generally true.

The diagram, Plate II. (b), shows the effect of change of air temperature. The heart beat was quickened from 70 beats to i 20 on the 3oth August, 1907, as compared with an acceleration of from 70 to 95 on the 14th March, 1907, though the man's temperature was practically the same in both cases. This is explained by the fact that he perspired exactly twice as much on the first occasion as he did on the second, his temperature 
being thus kept down. His temperature production in the two cases probably bore a very close relation to his heart beat. The chicf point in which the marching soldier differs from the walking civilian in this connection is the presence of constricting bands in the former which the latter is free from. On service this is not so much the case, as dress then soon accommodates itself to the exigencies of the situation, but on mancuvres in peace time, unless the soldier is allowed to loosen his collar there may be some constriction on the big blood vessels of the neck. Otherwise there does not, with our present equipment, seem much danger of interfering with the action of the heart directly.

This has not always been the case. There is a record in the life of a rather well-known soldier of fortune, Donald Monro, of "a Danish Captain who was accustomed to make the men of his company tie their cravattes very tightly, and use garters very tightly pulled below the knee, so that from the high colour of the face and the size of the calf they might appear more vigorous and better fed; but at the end of a certain time they almost all fell ill." In the case of the attack on Ching-KiangFoo, already alluded to, the pressure of the stocks on the blood vessels of the neck, played some, though not the chief, part in the disastrous result.

We now come to the effect of marching on the respiration. The increased combustion in the muscles demands increased oxygen and, therefore, an increased supply of air to the lungs. The civilian walking can get this in two ways: either by increasing the number of his respirations or increasing the depth of each respiration. He probably makes use of both methods, but the latter more than the former. Here, of course, is where the soldier is handicapped. He has in breathing to move either the walls of his abdomen or those of his chest, or both. But a movement of either is affected by the weight he has to carry. He cannot, therefore, make free use of the method of deepening his inspirations, and must rely more than the civilian on increasing their number; but every inspiration he takes means a certain amount of work expended in lifting or moving certain weights which come into close relation to the walls of his chest or abdomen. This is inevitable, to a certain extent. What is not inevitable is that the weights should be so disposed on his trunk; and supported by straps so placed as to exercise the maximum of restriction to the movements : of the chest and abdomen. In the old bandolier equipment every expansion of the chest had to work against three straps, viz.: the bandolier, containing fifty cartridges, and weighing 4 lbs. 9 ozs.; the haversack strap, supporting a weight of 2 lbs. 14 ozs.; and the water bottle strap; supporting a weight of 3 lbs. 12 ozs. Now, that cannot be called giving the chest fair play. I have already told you that no strap should cross the body above the belt, so as to allow of the coat being thrown freely open to 
encourage evaporation. There is an equally strong argument in its favour on the score of facilitating respiration and the movements of the chest.

I am aware that the question of how to carry the load is extremely difficult, especially when so large a part of it must consist of ammunition which must be so placed as to be accessible. I said that there was not much danger of our present equipment interfering with the action of the heart directly, but indirectly there is a very considerable danger, and for this reason:-Any impediment to the respiration means that the blood that is going to the lungs to get purified, on its way from one side of the heart to the other, becomes checked, and tends to head up towards the right side of the heart. At the same time the blood comes in to that side, from the body generally, unchecked, and the right side of the heart and even the liver become overloaded and distended.

The third effect of marching is loss of the body weight. This is due to more than one cause, but, undoubtedly, the preponderating cause is loss of moisture by perspiration. This loss of moisture is, of course, directly proportional to the heat produced. In itself it is a healthy reaction. - But it is considerably greater than one would at first suppose. Thus you will see from the diagrams (Plate III.) that Private Beach, of the Yorkshire' Regiment, lost on the 2oth August, 1906, as much as 4 lbs. of weight in a march of seven miles across the Long Valley. The greatest weight lost by any one of the five men who made that march was higher than this, about $5 \frac{1}{4}$ lbs. This represents about half-a-gallon of water taken out of the system. The relationship of this loss to the efficiency of the soldier is of the very greatest importance. The body of a man who weighs ten stone contains rather over $88 \mathrm{lbs}$. of water. Of this he can afford to lose a certain amount only, and no very great amount. Any loss amounting to one-tenth of the total, that is, less than 9 lbs., unless replaced at once, means death, and long before that point is reached, naturally, exhaustion will have set in. Now, in the above case one of the men lost more than half the total permissible loss, and it is probable that a very little more would have resulted in his breaking down. The noticeable part of this is that these were not untrained men, but privates towards the end of the drill season. The importance of this loss of weight is that the great and debatable question of drinking on the march must be settled in definite relation to the amount of water lost, because this loss of water means a heightening of the specific gravity of the blood, a thickening of it, so to speak, and this thickening, if allowed to go too far, will eventually diminish the power of perspiration, and, therefore, the power of cooling the body, with results that can best be stated as heat stroke. Now, of course, there are two kinds of thirst: the thirst of habit, and the thirst of necessity. $:$ The former thirst is a habit that anyone can be 


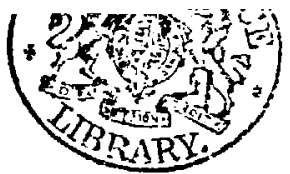

THE PHYSIOLOGY OF THE MARCH.

trained out of, and one which every soldier should systematically be trained out of. It is very different with the thirst of necessity, which is the cry of the thickened blood for water. This is the thirst you cannot train men out of, or at least, only to a small extent and with exceptional men. And besides, though you may train a man to disregard the sensation of thirst in his mouth, which is the outward expression of the actual deficiency of water in his blood, you cannot get round the fact that as long as he is working his muscles he is producing heat, and that if that heat cannot find its natural outlet, it will accumulate in his body, and the end of that is heat stroke. If you want to press your men they must have water, or else they will not get through the march, or if they do; will be fit for very little at the end of it. I am as great an advocate as anyone can be for water discipline, that is, for training the men to abolish the thirst of habit. . But there I stop. The great advantage of doing away with the thirst of habit is, that you can then tell when the : real thirst begins, the physiological thirst that must be gratified if the human machine is to keep running. I will give an actual instance, illustrating the necessity of attending to this point. If you will go to London Bridge on a hot day in the summer, you will find buckets of oatmeal water set there for the omnibus horses. These were placed there originally because the General Omnibus Company found that the death rate and sick rate of their horses from heat stroke was so high, without this watering, that they had to make these special arrangements. ' Of course, their motives were purely commercial, and it has been found to pay. Therefore, in arranging for a forced march, it is wise to take particularly good care to see that there is as much water as can be got for the men.

There are two other points in connection with this subject of the march, pure and simple, and those are the question of halts and the effect of training. On neither of these is it necessary to say much. Halts have the effect of allowing the men's temperature to come back to normal, their pulse rate to lower, and the respirations to fall in number. The effect is fairly quickly felt. Thus, taking the pulse rate in an actual case. A man doing in fifteen minutes an amount of work equivalent to 32 foot-tons, that is equivalent to the work that a 12 stone man would do carrying roo lbs. one mile, raised his pulse to 132 beats per minute from $6 \mathrm{I}$; after two minutes' rest it fell to. 100 ; after five to 82 ; after ten to 77 ; and after fifteen to 70 . From what ' $I$ have already said it follows that the frequency of halts should be regulated a great deal : by the temperature, but even more by the moisture of the day. Marching small bodies of troops; a brigade, say, it seems to me to be a mistake to order a halt every hour, or at any stated period. The proper test for the time when to halt is the condition of the men at the rear of the column. One halt every hour for five minutes is a good general rule, but it is a mistake to 
be too rigid. The best criterion is the condition of the men at the : rear of the column. A wise man : takes his weight off his horse's back wher he halts, and a wise man will take the loads off his men's backs too, even at a short halt. With the present equipment this is easy, which is one of its greatest advantages. Field equipment should be so designed that it may be taken off and put on by the man himself in one motion. The great importance of getting the equipment off is that it not only takes the weight off the man, but that it also allows the moisture to evaporate from parts that have been covered by the greatcoat or sack. There is an old saying of General Stonewall Jackson's that a man rests all over when he lies down, and there is a great deal of truth in it. ${ }^{2}$ As it is well known that the pulse and respiration are slower when lying than when sitting, there seems a sound physiological basis for doing so. As to training, the effect of this in reducing the rise of temperature, etc., is very striking. It is not merely a case of physical condition, since the four men of the Yorkshire Regiment, that were the subjects of the experiment, were in good enough physical condition at the start. These men marched the set march at the beginaing of the series, carrying a load of $2 \mathrm{lbs}$. only, and the same after three weeks' regular marching carrying 7 pounds. The temperature of the air was practically the same on both days. On the first occasion the average increase in the pulse beat was 43 in the minute, in the temperature 2.I degrees, and the loss of weight was $3^{\frac{3}{4}}$ lbs. On the second occasion the increase in pulse beat was 22 beats, in temperature 1.2 degrees, and the loss of weight only $2 \frac{3}{4} \mathrm{lbs}$. The difference when the man starts untrained is even more striking. Thus, in the case of Dr. Pembrey, the rise in pulse at the beginning was 72 to the minute, in temperature 2.2 degrees, and the loss of weight $2 \frac{3}{4} \mathrm{lbs}$. At the end of the period his pulse increased 28 beats only, his temperature 6 of a degree, and the loss of weight was under two pounds. It is hardly necessary to tell you that training improves a man's capacity for marching, but one would hardly anticipate that taking men in good condition the mere practice of route marching repeated steadily several days a week for three weeks would have made so marked a difference.

An ordinary march may be taken at 15 miles, requiring an expenditure of energy equivalent to 1,350 energy units; on the

1 The following quotation is of interest in this connection. It is extracted from "Twelve Years of Military Adventure," by Lieutenant Blakiston, who served in the later battles of the Peninsular War, in a Portuguese Battalion in the Light Division. "Our system of marching was calculated as much as possible to lessen the fatigue of the troops. During a march of about 12 miles or so we always made two halts, when the sotdiers immediately took off their packs and lay down, each company resuming them only just in time to admit of its marching off in time." Vol. II., pp. 176-7. 
supposition that the man weighs ro stone, and carries the ordinary heavy marching order of the Infantry private. 'This expenditure of energy is about three times as great as the actual effective work produced, since the human engine possesses a very high : factor of efficiency, greater than that of any steain engine. This rule is true, however, only for comparatively' moderate distances. As soon as fatigue begins to be felt the engine begins to work uneconomically, that is the amount of energy expended bears a higher ratio than before to the effective output of work. Already by the end of 15 miles some effect is felt in this direction, the expenditure of energy having in some cases been observed to rise by one-fifth. Each successive mile has a greater effect than the last. We see a closely. analogous instance in the case of steam engines. Every horsepowęr over a certain amount demands an excessive expediture of ' fuel, and the difference between 20 and 22 horse-power in this respect is enormously greater than that between ro and 12 . The human engine is similarly affected by pace, as already stated, but it is also affected by duration of activity, because, unlike all other engines, the body has to be self-stoking, self-repairing, and self-cleansing. These two last functions cannot be carried out satisfactorily while the engine is at work, and, therefore, the need for bodily rest. Now if you lengthen the march you shorten the period of rest, while at the same time you disproportionately increase the amount of unproductive expenditure of energy as I have already stated.

Repeat this day after day, and you can at once imagine the engine getting clogged by the waste products it cannot get rid of, and also weakened by the lack of repair of worn out parts. You can, at the same time, understand how forced marching breaks up even the best disciplined force, not because the men won't march, but because, after' a certain time, they can't march. Of course, forced marches have to be made, and if they cause the breakdown of a third of the force that does not make them any the less necessary. But their effects can be minimised. In the first place the load can be decreased. It is, of course, the question of whether it is better to go light and want your comforts, or to have your comforts and be too tired to appreciate them. Much must depend on the climate, but a young, healthy soldier ought to be able to stand a good deal of exposure, while flesh and blood, not being metal, his muscles cannot do more than a certain amount of work. The second resource is to feed the men. The energy necessary for every foot pound of work you do is supplied by a certain amount of food, or else by a certain amount of destruction of tissue. If the work is very severe, the latter always occurs, and it has been proved by direct experiment on athletes that the harder trained a man is, the better he can stand this waste. This waste can be checked by a liberal supply of food, 
which is, unfortunately, just the thing that is so hard to manage on a forced march of any duration even by the use of emergency rations.

Last, and to my mind the most important of all, is the question of water. As 1 told you before, if a man loses more than a certain amount of water from his blood in the way of perspiration, he will stop perspiring and his temperature will mount up. Not only this, but the thickened blood will be unable to remove the waste products of the process of combustion that has been going on in the muscles; this can only be carried on unsatisfactorily at the best, while work is going on, and $I$ am, therefore, not speaking so much now of the water supply on the road. It is the water supply on arrival at camp

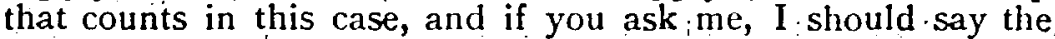
more the better. Of course, the question will always come in : Is it better to give the men their fill of doubtful water, or stint them to a limited supply of good? That depends entirely upon circumstances. If the march is the chicf object, that is, if it is necessary to get to a certain point in a certain time, you must chance the purity of the water. Without water the men will not get there at all. Of course, the result may be an outbreak of ; enteric fever or dysentery at a later period, but if you have attained your objective in the meantime; that must be risked.

On the question of the pace of a forced march, it is, I think, of interest to note that in an order issued by General Stonewall Jackson in April, 1863, not long before his death, and, therefore, with all the experience of marching that he had had in the Shenandoah Valley behind him, he lays it down at one mile in 25 minutes, with a ten minutes' halt every hour: This we should count as slow; as it only means two miles an hour, and, of course, that entails the men; being much longer on their feet than a quicker pace would.

The whole subject of marching, both ordinary and forced, is one which still demands careful experimental observation. 


\section{PLATE I.}

\section{EFFECTS ON BODY TEMPERATURE OF LOAD CARRIED.}

Temperature of Air (Wet Bulb) and Clothing.

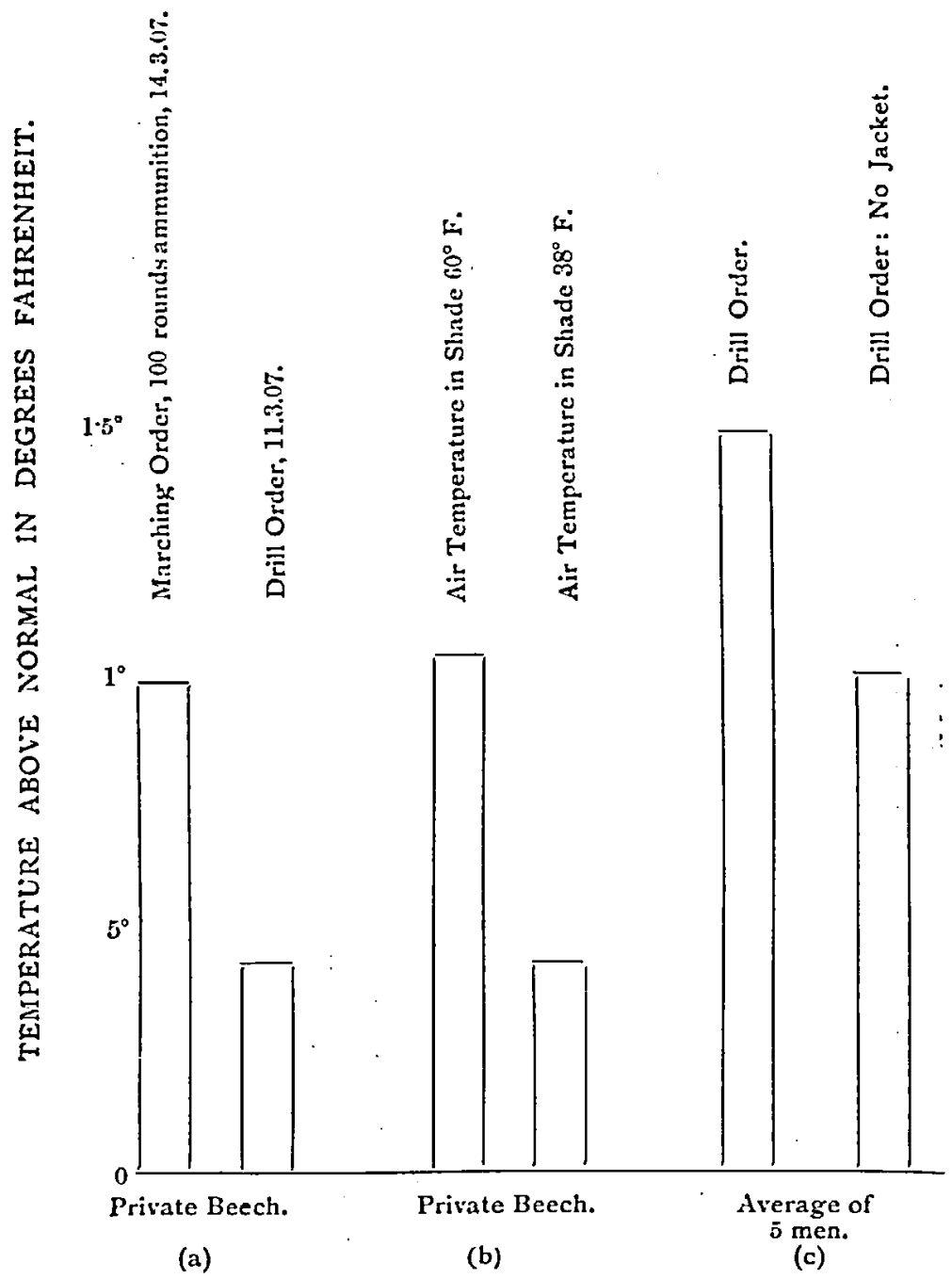


PLATE II.

EFFECT ON PULSE RATE OF LOAD CARRIED.

Temperature of air and Clotming.

皆 26 采

运 2

tric

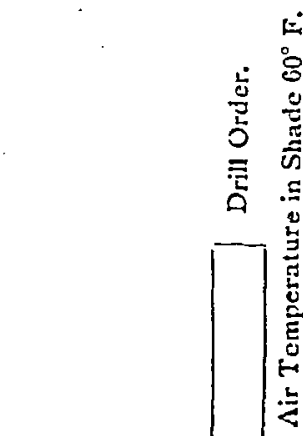

E.

8

טี

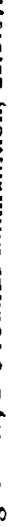

告 23 先

a

22

온 10

S 14

空 12

in

8

c

4

0

Private Becct.

(a)

Private Beech.

(b)

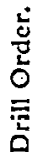

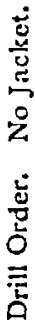
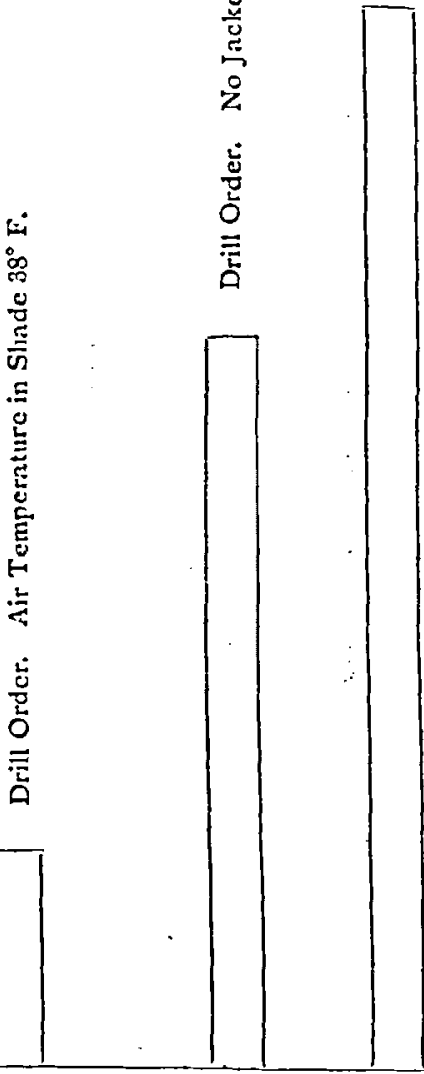

Average of -

5 men.

(c) 
THE PHYSIOLOGY OF THE MARCH.

PLATE III.

EFFECT ON LOSS OF WEIGHT, OF LOAD CARRIED.

Temperature of Air and Ciothing.

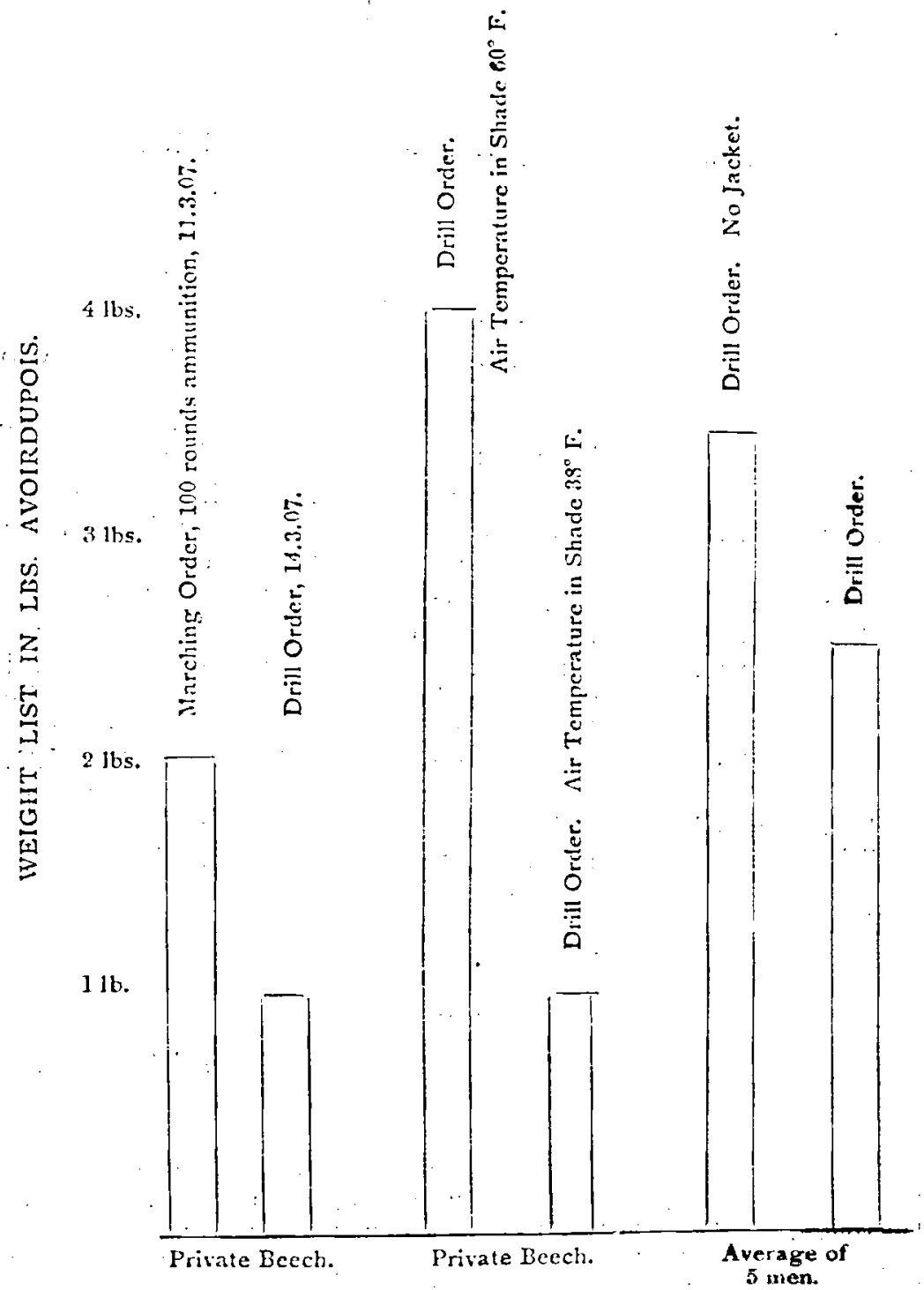

